\title{
A REVIEW: MECHANISTIC INSIGHTS INTO THE EFFECT OF THYROID DISORDERS ON ESTROGEN LEVEL AND BONE MINERAL DENSITY
}

\author{
MINAKSHI JOSHI*, SHRADHA BISHT, MAMTA F. SINGH
}

Sardar Bhagwan Singh Post Graduate Institute of Biomedical Sciences and Research, Balawala, Dehradun 248001

Email: monujoshi12354@gmail.com

Received: 04 Jun 2019, Revised and Accepted: 02 Sep 2019

\begin{abstract}
Thyroid hormone serves as an indispensable component for the optimum functioning of various biological systems. They curb body's metabolism, regulates the estrogen level, regulates bone turnover, essential for skeletal development and mineralization. Within the scope of knowledge, it is intimately familiar that thyroid disorders have widespread systemic manifestations, among which in hypothyroidism, even though elevated TSH (thyroid-stimulating hormone) may reduce estrogen level which in turn stimulates osteoclasts and thus cause osteoporosis, while hyperthyroidism accelerates bone turnover. Hypothyroidism does not directly interfere with the skeletal integrity, but treatment with levothyroxine for the suppression of TSH to bring the hypothyroid patient to euthyroid state for a long haul; lead to simultaneous reduction in bone mass and in (bone mineral density) BMD.
\end{abstract}

After the initial relevation of the correlation between thyroid disorders and osteoporosis in numerous studies have emphasized that both hypo and hyperthyroidism either directly or indirectly affects the bone mineral density or leads to the progression of osteoporosis.

Therefore the present study is aimed and so designed to review all the possible associations between them and the impact of thyroid disorders on estrogen level and bone mineral density.

The main findings of this review indicate that both excesses as well as deficiency of thyroid hormone can be potentially deleterious for bone tissue.

Keywords: Bone cells, Bone mass, Calcium, Chondrocytes, Estrogen, Interleukins, Levothyroxine

(c) 2019 The Authors. Published by Innovare Academic Sciences Pvt Ltd. This is an open-access article under the CC BY license (http://creativecommons.org/licenses/by/4.0/) DOI: http://dx.doi.org/10.22159/ijpps.2019v11i10.34447

\section{INTRODUCTION}

Osteoporosis is one of the most plebeian progressive skeletal diseases described by the quirky disorientation of bone tissue and bone mass. It can affect a person of any age, gender and groups, but in older people, there is a steep increase in the incidence of fracture [1]. The struts that make a mesh-like structure within bones become thin, causing the bone to become fragile, which lead to break them easily and increases the incidence of fracture [2].

Breaking of bones and fragile bone has the same meaning and sometimes we can use both the terms interchangeably. In osteoporosis, the susceptibility to fracture gets increased which is characterized by abnormal architectural arrangement of bone tissue [3]. In a person with osteoporosis a minor bump or fall is sufficed to break the bone [4]. The most common parts that get affected by osteoporosis are the spine, hip, wrists (forearm) and shoulder [5]

There are two main hypotheses which we can relate to the development of osteoporosis. The first one is-ineluctable breakdown of bones due to changes in bone matrix which leads to wasting of bones and other tissue. It is generally associated with age. The second one is the nutritional hypothesis which generally accomplishes two main nutrients (calcium and protein) [5]. A report was also released by the United State government in 2004 with a recommendation for physician that, it is mandatory to adopt a pyramidal approach for osteoporosis. The third level includes treatment either with anabolic medications or antiresorptive medications. The second level includes the management and secondary cause of osteoporosis and the baseline include nutrients such as calcium and Vitamin D as well as physical therapy such as fall prevention [6].

If osteoporosis remain untreated for a long haul it gives rise to unnecessary extreme pain, altered body posture, disability in moving, climbing stairs and increased mortality [7]. Spinal fracture sometimes called vertebral fracture, which may lead to quirky curvature of the spine and loss of height [8].

With the wide range of condition Receptor activator of nuclear factor $\kappa \beta$ ligand (RANK-L) is responsible for mediating the osteoclast-mediated bone resorption [9]. RANK-L (317 amino acid peptide) is the bone-specific gene and have a major role in stimulating, differentiation and inhibition of osteoclasts apoptosis [10]. For physiological reclamation of osteoclast some kind of cells and cytokines are responsible. In the bony surface the monocyte osteoclast precursors, activate, proliferate and fuse to form multinucleated osteoclasts and expresses a "receptor on their surface, for the activation of nuclear factor k-beta (RANK). In the presence of trophic factor M-CSF (Macrophage colony-stimulating factor) RANK-Ligand binds to this receptor. Binding of RANK-L to RANK, transformed osteoclast precursor to mature osteoclast and the process of bone resorption will take place and a bone resorption pit is formed. Osteoprotegerin (another protein) prevents the binding of RANK-L to RANK thus prevents bone resorption [11].

German pathologist Pomner originated the term osteoporosis by using three bone disorders. Osteomalacia (softening of bones) is a condition where a large number of unqualified bone tissue. It is due to the deficiency of Vitamin D and calcium. Osteoporosis (weak and brittle bones) is a condition where a large number of bone tissue are calcified and osteitis fibrosa, is a complication of hyperparathyroidism, where bone is eroded by osteoclasts and replaced with fibrous tissue [12]. The first case of osteoporosis was reported by Von Recklinghausen in 1891 in a young lady, who died due to hyperthyroidism with a feature of "worm-eaten appearance of long-bones", while in 1920 another researcher Plummer reported the same case with similar descriptions. Their finding indicates that thyroid disorder is a risk factor for osteoporosis and routine monitoring of thyroid hormones is mandatory [13]. Osteoporosis characterized by excessive bone loss, too little bone formation, or a combination of both [14]. 


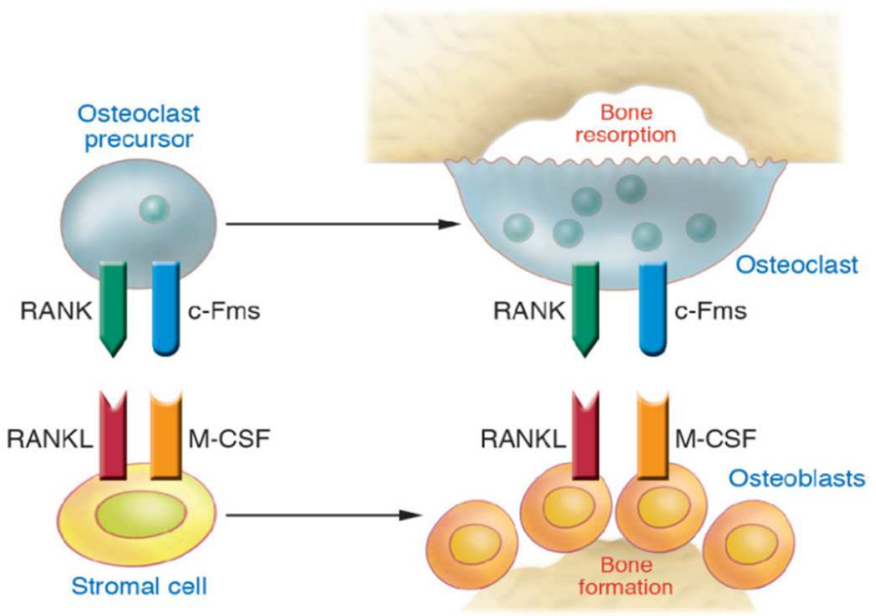

Fig. 1: Schematic diagram for bone formation and bone resorption [11]

\section{Classification}

In order to achieve the information on facts (diabetes, endocrine disorder (a thyroid disorder), that affect bone metabolism, osteoporosis can be divided into two types.

\section{Primary}

The exact cause is unknown but can be associated with aging. Conditions such as menopause may accelerate that.

Despite this Primary osteoporosis can be further divided into two types. Involutional osteoporosis, type-1 (due to deficiency of estrogen and also known as postmenopausal osteoporosis) and involutional osteoporosis, type-II (loss of bone mass due to aging of trabecular and cortical bones thus also called as senile/doddering osteoporosis).

\section{Secondary}

Is caused by something else, factors such as genetic disease (cystic fibrosis, Marfan syndrome and Gaucher's disease), endocrine disorders (Cushing's syndrome, hyperparathyroidism, thyrotoxicosis, hyperprolactinemia and diabetes mellitus), Gastrointestinal disorder (Celiac disease and Malabsorption) and medications such as prednisone are responsible for the development of secondary osteoporosis $[15,16]$.

Idiopathic Juvenile Osteoporosis (IJO) with unknown causes and occurs just before the onset of puberty, but the lucky one experience complete recovery of bone. Average age at onset is seven years while the range is 1 to $13 \mathrm{y}$ [14].

\section{Epidemiology}

A large number of populations are suffering from osteoporosis, this attracts the attention of orthopedic surgeons and physician in North America and Europe and this comes to lightning as a very common disease. Osteoporosis is an alarming issue in some countries such as India. Although it is a sun-rich country, still deficiency of vitamin D is a very common issue for the people of any age but women's are more susceptible to osteoporosis. It has been estimated that till 2015 about 230 million Indians have been diagnosed with osteoporosis among which $20 \%$ are women [17]. The Third National Health and Nutrition Examination Survey revealed that in the U. S. up to 13 million men having age 50 or more than 50 , have low bone mineral density (BMD) and from these up to 02 million people having osteoporosis [18]. For British white women with age of $50 \mathrm{y}$ the incidence of osteoporotic fracture of hip, spine and radius is $14 \%, 11 \%$ and $13 \%$, respectively but the incidences are high for North American women and i.e. $17.5 \%, 15.55 \%$ and $16 \%$ respectively. In whites (European) hip fractures are more common among all other kinds of fracture [19].

\section{Risk factors}

Insights are drawn from the scholarly literature the potential risk factors that can predispose to osteoporosis are shown in the table $[15,19]$.

Table 1: Risk factor associated with the progression of osteoporosis

\begin{tabular}{llllll}
\hline Skeletal & Behavioral/social & Extra skeletal & Nutrients & Medical history & Medication \\
\hline Low body & White. & Increasing Age. & Lack of & Diabetes mellitus type 1. & Cytotoxic agents, \\
mass index. & Cigarette smoking. & Abnormal gait. & calcium. & Untreated & heparin, lithium, loop \\
Reduced & Exuberant Alcohol & Dementia, & Vitamin D & hypogonadism. & diuretic, oral \\
BMD. & consumption & previous falls. & & Low body weight. & glucocorticoids, \\
$\begin{array}{l}\text { Previous } \\
\text { fracture. }\end{array}$ & Tobacco consumption & Poor & & Malignancy. COPD. & immunosuppressants. \\
Bone & Desk- & coordination. & & Hyperparathyroidism & Stroke, rheumatoid \\
turnover. & bound/sedentary & & & arthritis, sex hormone \\
Bone & inability. & & & deficiency. \\
architecture. & & & & &
\end{tabular}

Osteoporosis is considered as a silent disease [20] because people are less aware of it and do not experience any symptoms prior to the fracture. The pain from which a patient is going through consider it as a part of its normal routine resulting the patient remains untreated and undiagnosed from osteoporosis. Gender is the most dominant risk factor for osteoporosis. The bones of postmenopausal women are more susceptible to fracture than premenopausal due to diminished levels of estrogen (by hypothyroidism), which reduces absorption of calcium. For maintaining the estrogen level kept in line plant phytoestrogens are considered to be best. In the true sense they are polyphenolic in nature and due to large content of antioxidant they also possess anti-osteoporotic activity [21].

Another key point to remember is that, in order to prevent the chances of osteoporosis, for the correct and normal functioning as 
well as for the concordant development of bone there are some factors that has to be focused, such as genetic conditions, metabolic, hormonal homeostasis, mechanical load, and balanced diet. Fractures that are caused by falling from the height are not considered as the osteoporosis fracture because people presenting such type of fracture have normal bone mineral density (BMD) as well as the normal architectural arrangement of bone tissue, while the reduced BMD (osteopenia) [22], bone fragility and abnormal architectural arrangement are the representatives of osteoporosis fracture.

\section{Pathogenesis and assessment of osteoporosis}

The pathogenesis of osteoporosis accrued by aging, lack of estrogen (menopause), thyroid disorders and excessive release of cytokines (play a major role in the regulation of bone resorption) due to chronic inflammatory disease and increased oxidative stress [10].

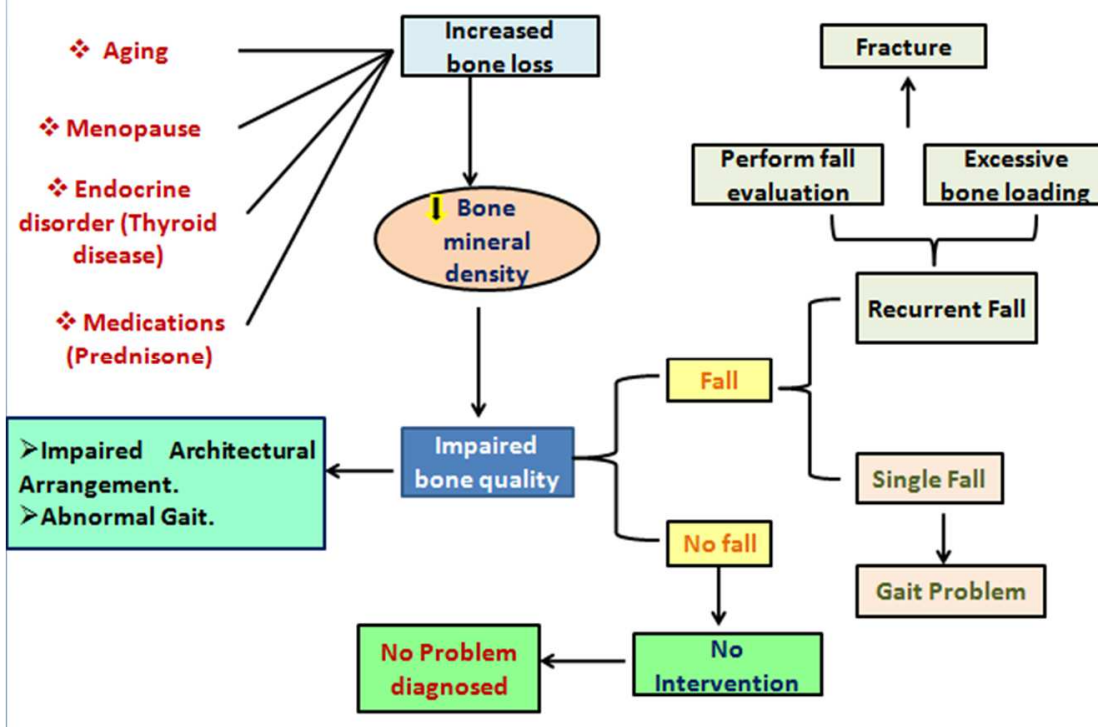

Fig. 2: Pathogenesis and assessment of osteoporosis [8]

Rossini $\mathrm{M}$ et al. Evaluated the adverse reactions and safety issues of drugs used in the management of osteoporosis. Their findings suggest that a large number of licensed drugs are used in the treatment of osteoporosis over the last 2 decades, some of them are listed below, such as-Calcium, Vitamin D, Bisphosphonates, selective estrogen receptor modulators, denosumab and teriparatide having long term safety, while the license for treating osteoporosis with calcitonin was recently withdrawn [23].

Osteoporosis is somehow, somewhere linked with endocrine disorders (a thyroid disorder), so the central issue addressed here is to establish the link between thyroid disorder and Osteoporosis.

How thyroid hormone affects the skeletal integrity and what are their effects on human physiology can be assessed by examining the adverse consequences of both (hypo and hyperthyroidism). Among thyroid disorder, hyperthyroidism independently accountable for the prolonged activation of osteoclast which leads to the induction of bone loss in adults, while hypothyroidism is not a potent risk factor for osteoporosis [24]. Overproduction of thyroid hormone from butterfly-shaped endocrine gland can be responsible for deterioration of bone by misbalancing the rate of formation of a new bone and bone resorption collectively known as bone turnover, that generally takes $200^{+}$days, but in case of hyperthyroidism this cycle takes only 130-140 d for the completion; thus bone turnover hasten by hyperthyroidism and an increase in bone turnover is a familiar risk factor for osteoporosis fracture [25]. The patient has any kind of thyroid problems, especially overt hyperthyroidism generally suffers from proximal limb muscle weakness (proximal myopathy), which upon treatment get resolved [26].

Influence of thyroid hormone on growth and development of bone: molecular mechanism

The actions of thyroid hormone on bone are mediated by thyroid hormone receptors (TRs) such as THR alpha 1, alpha 2 and THR beta1, beta 2 . And these THRs are encoded by THRA and THRB genes. During bone growth tri-iodothyronine stimulates bone mass, thus exerts its anabolic effect, but has a catabolic effect on adult bone and stimulates bone turnover. Not only throcytes but the majority of human cells and tissue express thyroid hormone receptors on their surface. Deficiency of thyroid hormone in children leads to delayed bone age, arrest in bone growth followed by epiphyseal dysgenesis and retardation in skeletal development [27].

(A) In hypothyroid state the activity of Iodothyronine Deiodinase 2 (DIO2) is considered as maximum while the activity of Iodothyronine Deiodinase 3 (DIO3) is minimum due to this factor the thyroid hormone receptor called thyroid hormone receptor alpha 1 (TR $\alpha 1$ ) binds only to corepressor, thus remains unliganded and inhibit $\mathrm{T} 3$ target gene transcription. (B), in the euthyroid state, the optimized intracellular activity/availability of T3 is mediated by D2 and D3, by which the displacement of co-repressor takes place. (C), despite this In case of thyrotoxicosis (a reverse form of hypothyroidism), the activity of D3 is maximized while the activity of the D2 is minimized, thus T3 gene transcription enhanced due to prolonged/increased activation of TR $\alpha 1$ [28].

Osteoblasts, osteoclasts, osteocytes and chondrocytes are the major component required for the growth and maintenance of bone cells, among which osteoblasts and chondrocytes are directly related to thyroid hormones and are responsive to thyroid hormones. The activity of osteoclast is also sensitive to changes in thyroid status [29]. An established cause of secondary osteoporosis is considered as thyrotoxicosis while the change in thyroid status due to abnormal thyroid hormone signaling has recently been identified as a novel risk factor for osteoarthritis [30]. The process of proliferation and differentiation of bone cells, including chondrocytes, osteoblasts and osteoclasts is regulated by thyroid hormone [31].

Both osteoblast (bone-forming cells) and osteoclast (absorb bone during growth and healing) get stimulated in response to thyroid hormone. But the action of thyroid hormone in osteoclast is more prominent, resulting grievous reduction in bone mass. In order to achieve a euthyroid state with the suppressive dose of levothyroxine is responsible for decreasing bone mass and bone mineral density, which are associated with increased fracture risk [32]. 


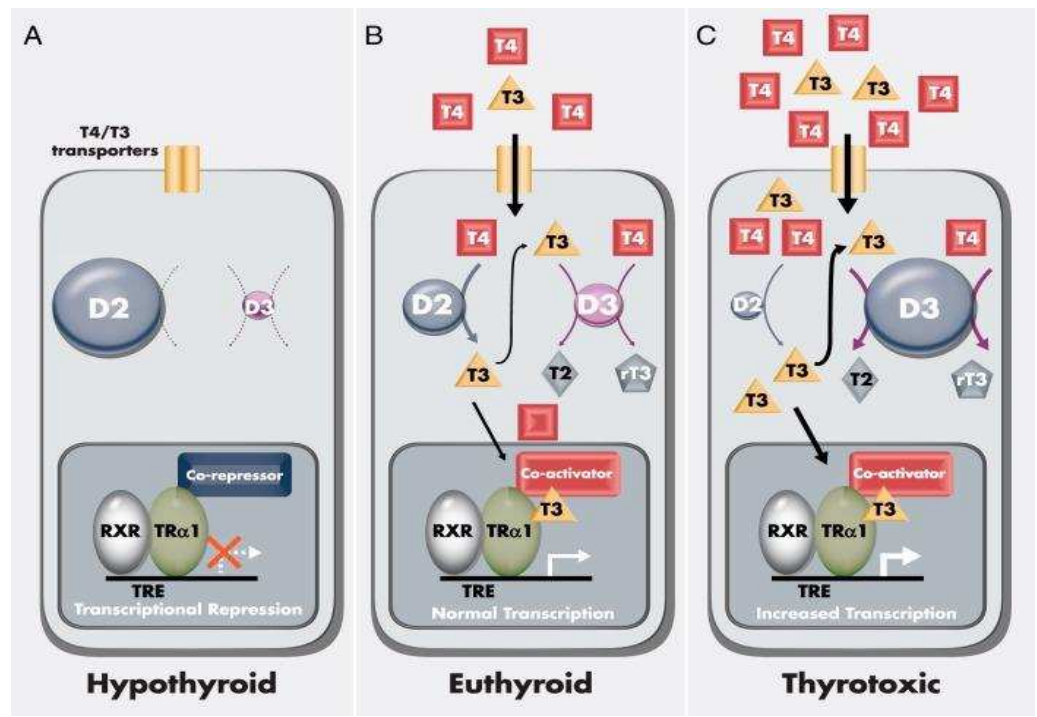

Fig. 3: Influence of thyroid hormone on bone cells [28]

Douglas C, et al. in his prospective study evaluated that in the older women low level of thyrotropin is not associated with bone loss. He noticed that in postmenopausal women, having age above $65 \mathrm{y}$, low level of thyroid hormone as well as TSH are not linked to bone loss [33]. Another study has been carried out by Susan L, et al. for the evaluation of the outcomes of skeletal function from the treatment of levothyroxine for a long haul in pre as well as postmenopausal women. They provide a positive data along with supportive evidence that indicates treatment with L-thyroxine for a longer duration might bring changes in skeletal integrity and associated with a depreciated bone mineral density of the hip and spine [34].

A study, which was conducted on a large number of populations indicates that thyroid function abnormality directly or indirectly might be associated with increased fracture risk and reduced bone mineral density that can affect both sexes [35]. Greet Roef et al. have evaluated that physiological range of thyroid hormones affects the peak bone mass and bone density in a healthy man. They noticed that In healthy men at the age of peak bone mass, between-subject variation in thyroid hormone concentrations affects bone density, with higher levels of FT3, TT3, TT4, and TBG being associated with less favorable bone density and content [36].

\section{Influence of hyperthyroidism or subclinical hyperthyroidism on skeletal health}

Hyperthyroidism is a condition indicating the excess circulating level of thyroid hormone combinelly known as T3 and T4. In childhood, excess thyroid hormone cause premature accretion of growth plates, cranial sutures which ultimately lead to craniosynostosis and short stature. While a reduced bone mineral density and increased bone turnover is observed in hyperthyroid adults [37]. Despite this improvement in bone mineral density is observed on treatment of hyperthyroidism to euthyroid state [38]. Studies reveal that hyperthyroidism has a prejudiced effect on bone mineral density leads to reduced bone mass and increases the risk of fracture [39].

In the patient of hyperthyroidism the urine as well as fecal excretion of calcium get increases by three to four times due to alterations in the metabolism of calcium and phosphorus made by a hyperactive thyroid gland (hyperthyroidism) resulting in a condition termed as hypercalcemia. In contrast, to control subjects, the mean serum calcium level of hyperthyroid patients are 2-3 times higher and this is due to abnormal efflux of calcium from the kidneys, skeleton and gastrointestinal tract [40]. In pre osteoblastic cells, it has been observed that tri-iodothyronine increases the expression of mRNA of RANKL (key molecule responsible for the activation of osteoclast and osteoclastogenesis synthesized from osteoblasts) [41, 42].

\section{Subclinical hyperthyroidism}

Subclinical hyperthyroidism is a condition characterized by low or undetectable serum levels of thyroid-stimulating hormone (TSH), while the levels of thyroid hormones (T3 and T4) remain unaffected. Low or undetectable TSH levels are associated with increased bone turnover markers, especially in postmenopausal women [43]. In the body of literature, it has been indicated that subclinical hypothyroidism is associated with reduced bone mineral density and increases the risk for a bone of getting fractured especially in women [41].

Mudde $\mathrm{AH}$, et al. has evaluated the peripheral bone density in women with untreated multinodular goiter, he noted that subclinical hyperthyroidism with multinodular goiter is associated with decreased BMD in pre as well as postmenopausal women. It has also been concluded from this study that bone mineral density of the forearm is decreased in women with subclinical hyperthyroidism [44]. Folds, J et al. have investigated the bone mineral density in patients with endogenous subclinical hyperthyroidism. Dual X-Ray absorptiometry was used for the measurement of the bone mineral density of the lumbar spine, femoral and Neck. This study concluded that in postmenopausal women with subclinical hyperthyroidism, there is a decrease in bone mineral density of spine, femoral neck and forearm, while no significant effect is seen in premenopausal women with subclinical hyperthyroidism [45].

MC Dermott et al. have observed a longitudinal assessment of bone loss in women with levothyroxine suppressed benign thyroid disease and thyroid cancer. In contrast to controls, the rate of bone loss was greater in levothyroxine suppressed patients. In aggregate insights drawn from this article suggests the association between bone loss (cortical region) and levothyroxine suppression that indicates a reduced bone mineral density [46]. Campus-pastor MM, et al. noted that there is a significant decrease in bone mineral density in the lumbar spine, femoral neck and ward triangle in postmenopausal women. Their findings suggest that thyroid hormone exerts their deleterious effect on bone mineral density, which may turn into osteoporosis [47]. In 2010, Lee J, et al. and other-investigated the effect of subclinical hyperthyroidism on skeletal function and noted that the incidence of hip fracture increases in older patients with subclinical hyperthyroid function. They also concluded that the BMD of the femoral neck, but not of lumbar spine has been decreased in women with subclinical hyperthyroidism [48]. In 2015, Blum MR, et al. and others evaluated that subclinical hyperthyroidism was associated with an increased risk of hip and other fractures [49].

In order to achieve some other sort of information Vadiveloo $\mathrm{T}$, et al. noted that patients with endogenous subclinical hyperthyroidism 
are associated with increased fracture risk along with a hazard ratio of 1.25-1.26 and are associated with osteoporosis, which get abolished after the achievement of overt hyperthyroidism or thyroid state [50]. Another researcher Tauchmanova L, et al. in his crosssectional study indicated that there is a significant decrease in bone mass mainly cortical region in women with endogenous subclinical hyperthyroidism while a significant increase in the rate of bone turnover markers [51]. The controversial data obtained from the papers published in the JCEM indicates that there is no any relationship has been associated with subclinical thyroid function and bone mineral density $[52,53]$.

\section{Influence of hypothyroidism or subclinical hypothyroidism on} skeletal health

For perpetuation as well as maintenance of bone mass and growth of bone tissue thyroid hormone serves as an important factor. If hypothyroidism remains untreated for a longer period of duration the growth of bone tissue goes into a negative direction i.e. growth arrest. There is a decrement in the formation of bone cells, leads to growth retardation, short stature and the process of endochondral ossification get disturbed $[54,55]$.

Generally, hypothyroidism leads to a decrease in metabolism and also slows down other biological processes. Kosińska A et al. evaluated the effect of thyroxine treatment (substitute or suppressive doses) on bone turnover markers. They noticed that in pre and postmenopausal women the osteogenic and osteoclastic activity increases in treatment with thyroxine. Thyroxine when used as a suppressive dose it is solely accountable for the stimulation of bone turnover markers in comparison to substitute dose. There is an elevation in serum concentrations of vitamin D, parathyroid hormone while serum level of osteocalcin and alkaline phosphatase and the amount of urinary calcium i. e calciuria or calciuria has been decreased [56].

In the year of 2000 researcher Vestergaard $\mathrm{P}$, et al. evaluated the risk of fractures in patients having primary idiopathic hypothyroidism. They noticed that there is the development of temporary fracture of short duration of $2 \mathrm{y}$ and which was limited to forearm only, but the overall risk for a bone of being fracture is increased twice in comparison to control individuals [57]. Despite this, in order to achieve some extra information Vestergaard $\mathrm{P}$, et al. further evaluate the influence of treatment with antithyroid drugs and levothyroxine on fracture risk and the effect of hypo and hyperthyroidism. After diagnosis of hyperthyroidism the chances of fracture increased within the first $5 \mathrm{y}$, while after diagnosis of hypothyroidism the chances still increase within first $10 \mathrm{y}$. There is a significant increase in the reduction of fracture risk after treatment with antithyroid medications [58].

Ross DS noted that there is no significant reduction in bone mineral density of forearm and spine in postmenopausal women with subclinical hypothyroidism [59].

\section{Supporting attestation}

\section{Effect of thyroid disorder on estrogen depletion}

Thyroid autoimmunity is the most prominent cause of thyroid dysfunction, especially in the reproductive age women [60]. It is intimately familiar that thyroid hormone exerts their action by acting on thyroid hormone receptors that are present in the human ovarian surface epithelium [61]. Hypothyroidism adversely manipulates the female reproductive physiology in several ways, it disturbs estrogen metabolism, increases prolactin levels above 25 $\mathrm{ng} / \mathrm{ml}$, which in turn inhibits the pulsatile secretion of gonadotropins [62]. In hypothyroidism, there is an increase in the level of TRH, followed by increased secretion of TSH [63]. The follicle number and fertility has been decreased due to down regulation of thyroid hormone receptors (TRs) [64]. Hypothyroidism affects the female reproductive hormones, reduces the amount of sex hormone-binding globulin and androgen. It induces fluctuations in estrogen levels in females, which may lead to decreased amount of estrogen and testosterone, but the free level of these hormones gets increased [65]. Fluctuation in the level of estrogen leads to ovarian dysfunction; hence maturation of oocytes does not take place while other abnormalities are associated with depletion in the level of estrogen which directly or indirectly linked with the development of osteoporosis.

The metabolic clearance of estrone and androstenedione may get reduced and aromatization of peripheral estrogen may get increased $[66,67]$. The receptor-mediated action of estrogen gets reduced due to inhibition in binding activity of estrogen with its receptor by hypothyroidism [68]. A variety of dysfunctions which are adversely manipulated by hypothyroidism are menstrual irregularities, recurrent (higher) miscarriage rates, altered ovarian function and subfertility [69].

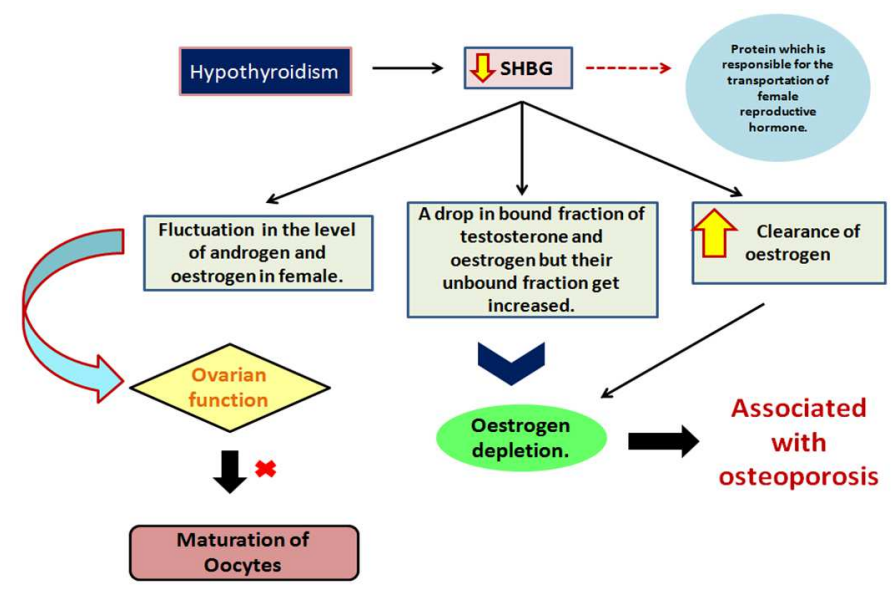

Fig. 4: Effect of hypothyroidism on estrogen level [65-67]

\section{Effect of estrogen on skeletal integrity: molecular mechanism}

The effects of estrogen on the bone matrix are complex, but it seems that estrogen plays a pivotal role in skeletal health. For the growth and maturation of bone estrogen is considered to be an important factor and in adults, it also helps in the regulation of bone turnover [70]. Estrogen exerts a protective effect on bone as estrogen receptors are found on osteoblasts and osteoclasts; thus the tissue of bone is responsive to estrogen [71].
In postmenopausal women there is a rapid bone loss, accelerates continuously after menopause. In postmenopausal women, it seems that bone resorption exceeds than its formation due to the declining level of estrogen hence women of postmenopausal age are more susceptible to osteoporosis [72]. Estrogen shield, bone loss by suppression of inflammatory cytokines such as interleukin (IL-1, IL6), slowing bone decay, and hence reducing fracture risk [73]. Teresa $\mathrm{S}$, et al. evaluated the bone protective effects of estrogen and 
the association between differential IL-1 receptor regulations in human osteoclast-like cells and identified that in bone marrow stromal cells and in primary human osteoblasts estrogen did not alter the level of IL-1receptor levels but control them. While during deficiency of estrogen level, especially in older women leads to osteoclast mediated bone loss [74].

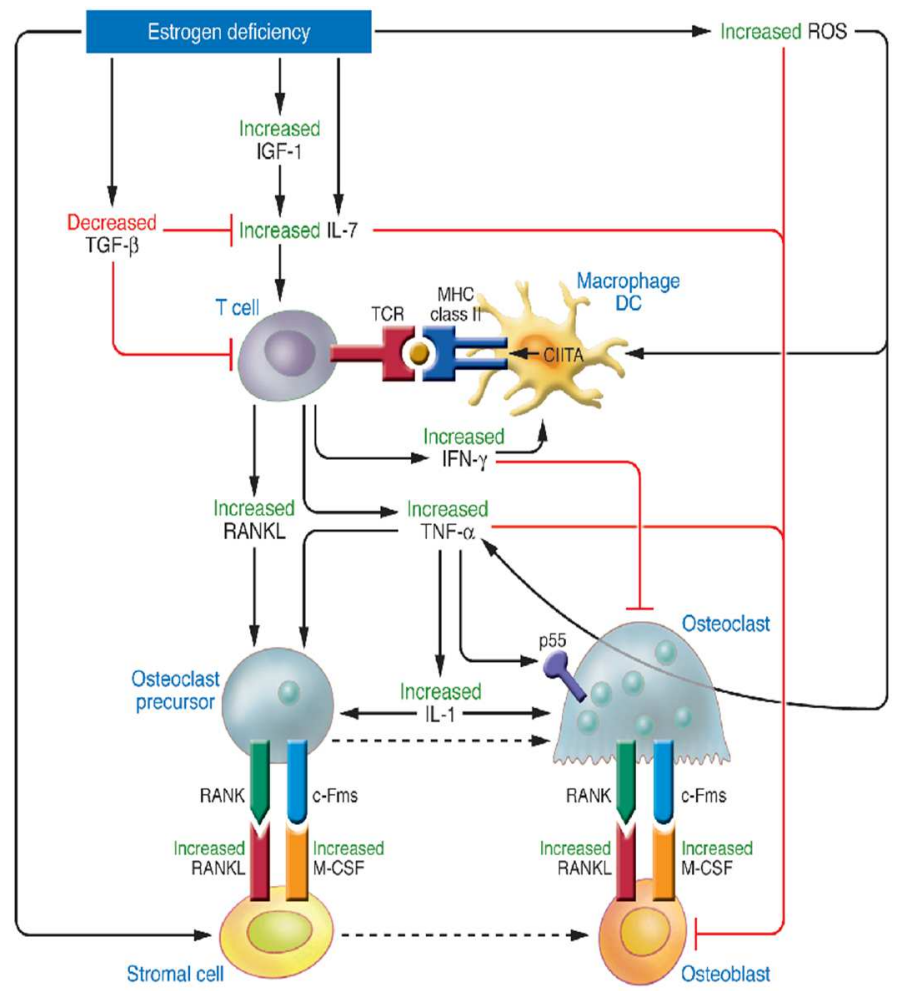

Fig. 5: Effect of estrogen on bone remodelling [11]

The bone loss, which leads to the deficiency of estrogen is represented and elaborates in this representational diagram. Estrogen is responsible for the apoptosis of cytokines and some hormones. On the other hand the interleukin-7 (IL-7) level increases when the level of estrogen decrease as well as decreasing the production of transforming growth factor-beta (TGF- $\beta$ ) and increase the production of insulin-like growth factor-1 (IGF-1). By this activation of $\mathrm{T}$ cell occurs which leads to the liberation of type II interferon (IFN- $\gamma$ ) which raises the antigen presentation which is necessary for triggering the $\mathrm{T}$ cell immune response. Low levels of estrogen also affects the antioxidant pathway by increasing the level of ROS [11].

Stimulation of inflammatory cytokines apoptosis and a reduction in osteoclastogenesis begins with the initiation of estrogen replacement therapy (ERT) and bone loss minimized to an extent after long term use of ERT [75].
The process of Bone resorption gets inhibited by estrogen followed by the synthesis of IL-1, IL- 6 , TNF- $\alpha$ and PGE2. These are the stimulator of osteoclast synthesis. Estrogen also exerts an antagonistic action on IL- 6 receptors, so transgenic mice lacking the IL-6 receptor do not develop osteoporosis [76]. The proinflammatory mediators IL-1 are involved in the pathogenesis of various diseases and increases the rate at which bone is lost. It also stimulates the progression of osteoporosis [77], followed by rheumatoid arthritis [78]. Estrogen, androgens, vitamin D and other circulating hormones, including parathyroid hormone regulates bone remodelling cycle.

Another mechanism indicates that osteoclast apoptosis is also regulated by estrogen. In the absence of estrogen the life span of osteoclast increases due to reduced apoptosis, which prolongs the resorption phase of the remodelling cycle [79].

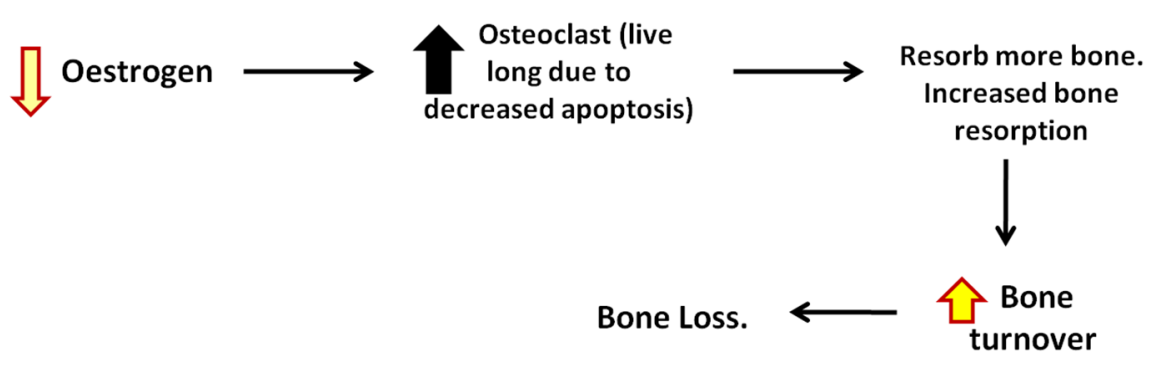

Fig. 6: Effect of estrogen level depletion on bone health

In postmenopausal women, estrogen replacement therapy improves Bone Mineral Density (BMD). Over 35 y ago, Lindsay and colleagues demonstrate that in oophorectomized women, the bone loss gets prevented by estrogen while withdrawal of estrogen exerts an 
opposite effect. Despite this it has been also established that like estrogen the other dominant sex hormone-like testosterone in man also regulates bone metabolism [80]. Zuo $\mathrm{H}$, et al. in their prospective, open-label, randomized controlled clinical trial evaluated the effect of menopausal hormone therapy on bone mineral density in Chinese women belonging to 03 groups, group (A) receiving $0.625 \mathrm{mg}$ conjugated equine estrogen (CEE) $+100 \mathrm{mg}$ micronized progesterone (MP) followed by group (B) receiving 0.3 $\mathrm{mg}$ CEE daily+100 mg MP and group (C) receiving $0.625 \mathrm{mg}$ CEE+10 mg dihydrogesterone daily. The results summarized above indicates that there is a significant $(\mathrm{P}<0.01)$ increase, i.e. $2.31 \%$ and $1.95 \%$ in bone mineral density of group A and $\mathrm{B}$. There is an elevation in bone mineral density of lumbar, femoral neck and ward triangle with both lower and standard doses of CEE with a reduced bone turnover [72].

\section{CONCLUSION}

On the basis of the evidence, it has been established that patient having thyroid disorder are at a greater risk of developing osteoporosis. A drop in the quality of bones has been observed in the person having any kind of thyroid disorder. Both hyper and hypothyroidism affect bone function in a very abysmal way and they are also the predictor of osteoporosis. From all the reported data, it's clear that thyroid hormone affects the development of bone tissue, and we are trying to generate the specific data, while the molecular mechanism is still very complex. Our study demonstrated that thyroid disorder is a frequent medical problem and require medical attention. Thyroid hormone serves as necessary components for the normal functioning of bone tissue.

In aggregate, our finding might help in refining the association between thyroid dysfunction and osteoporosis. Although it's not too difficult to assess the effect of thyroid hormones on skeletal integrity (bone mineral density, bone mass, bone cell), as well as in osteoclasts and osteoblasts, which in turn, reinforces the importance of early diagnosis of thyroid disorders.

\section{ACKNOWLEDGMENT}

It is a proud privilege for me to express my heartfelt thanks and gratefulness to all the persons who backed me directly or indirectly throughout the materialization of this work at this magnitude. I humbly bow my head in front of the "The almighty God", for his divine grace and blessings bestowed upon me at all the times.

\section{DATA SOURCE}

English language articles published from 1966 to 2019 were identified through searches of the MEDLINE, EMBASE database, SciELO Analytics, selected bibliographies and personal files using the key term osteoporosis, thyroid disorders, hypothyroidism, subclinical thyroid function, estrogen, bone mineral density, and osteoclasts. The search includes meta-analysis, randomized controlled trial, prospective cohort, cross-sectional retrospective studies, clinical studies, research and review articles. Search dates: January 01, 2019 to July 18, 2019.

\section{AUTHORS CONTRIBUTIONS}

All the author have contributed equally

\section{CONFLICT OF INTERESTS}

No conflict of interests

\section{REFERENCES}

1. Nanes MS, Kallen CB. Osteoporosis. Semin Nucl Med 2014;44:439-50.

2. Ferdous HS, Afsana F, Qureshi NK, Rouf RSB. Osteoporosis: a review. Birdem Med J 2015;5:30-6.

3. Dunnewind T, Dvortsin EP, Smeets HM, Konijn RM, Bos JHJ, de Boer PT, et al. Economic consequences and potentially preventable costs related to osteoporosis in the Netherlands. Value Health 2017;20:762-8.

4. Minisola S, Cipriani C, Occhiuto M, Pepe J. New anabolic therapies for osteoporosis. Intern Emerg Med 2017;12:915-21.

5. Nordin BEC. International patterns of osteoporosis. Clin Orthop Relat Res 1966;45:17-30.
6. Kling JM, Clarke BL, Sandhu NP. Osteoporosis prevention, screening and treatment: a review. Int J Womens Health 2014;23:563-72.

7. Lopez PJT, Lopez CF, Mora. Osteoporosis in patients with subclinical hypothyroidism treated with thyroid hormone replacement. Clin Cases Miner Bone Metab 2011;8:44-8.

8. Sozen T, Ozisik L, Basaran NC. An overview and management of osteoporosis. Eur J Rheumatol 2016;4:46-56.

9. Michael R, McClung E, Michael Lewiecki, Stanley B Cohen, Michael A Bolognese. Denosumab in postmenopausal women with low bone mineral density. New Engl J Med 2006;354:821-31.

10. Shobaky FEL, Kassem SS, Emtenan, Hanafi M, Saleh ZA, Badawy $\mathrm{I}$, et al. Rankl expression and metabolic changes in ovariectomized rats and the possible protection by vegetable formula. Asian J Pharm Clin Res 2018;11:318-21.

11. Weitzmann MN, Pacifici R. Estrogen deficiency and bone loss: an inflammatory tale. J Clin Invest 2006;116:1186-94.

12. Newton John-HF, Morgan DB. The loss of bone with age, osteoporosis and fractures. Clin Orthop Relat Res 1970;71:229-52.

13. Ale AO, Ogbera AO, Ebili HO, Adeyemo OL, Afe TO. Prevalence, predictive factors and characteristics of osteoporosis in hyperthyroid patients. Int J Endocrinol 2018;1-8. https://doi.org/10.1155/2018/3540256

14. Geetha S. Juvenile osteoporosis in children-a nursing perspective. Int J Curr Med Pharm Res 2017;3:2262-4.

15. Cosman F, de Beur SJ, LeBoff MS, Lewiecki EM, Tanner B, Randall S, et al. Clinician's guide to prevention and treatment of osteoporosis. Osteoporosis Int 2014;25:2359-81.

16. Hannan MT, Felson DT, Dawson Hughes B, Tucker KL, Cupples LA, Wilson PW, et al. Risk factors for longitudinal bone loss in elderly men and women: the framingham osteoporosis study. J Bone Miner Res 2000;15:710-20.

17. Khadilkar AV, Mandlik RM. Epidemiology and treatment of osteoporosis in women: an Indian perspective. Int J Womens Health 2015;7:841-50.

18. Gronholz MJ. Prevention, diagnosis and management of osteoporosis-related fracture: a multifactorial osteopathic approach. J Am Osteopath Assoc 2008;108:575-85.

19. Christodoulou C, Cooper. What is osteoporosis? Postgrad Med J 2003;79:133-8.

20. Kumar PRAV, Joseph AK, Gokul G, Alex MP, Naveena G. Clinical outcome of calcium, Vitamin D3 and physiotherapy in osteoporotic population in the Nilgiris district. Int J Pharm Pharm Sci 2016;8:157-60.

21. Pankova S, Tsvetkova D. Role of phytoestrogens in the prevention of osteoporosis. Int J Curr Pharm Res 2015;7:1-6.

22. Shende M, Mendhekar S. Formulation of poly herbomineral metrics for treatment of osteoporosis. Asian J Pharm Clin Res 2018;11:217-23.

23. Rossini M, Adami G, Adami S, Viapiana O, Gatti D. Safety issues and adverse reactions with osteoporosis management. Expert Opin Drug Saf 2016;15:321-32.

24. Cardoso LF, Maciel Lea MZ, de paula FJA. The multiple effects of thyroid disorder on bone and mineral metabolism. Arq Bras Endocrinol Metab 2014;58:452-63.

25. Cooper DS. Approach to the patient with subclinical hyperthyroidism. J Clin Endocrinol Metab 2007;92:3-9.

26. Tawaratsumida H, Setoguchi Takao, Arishima Y, Ohtsubo H, Akimoto M, Ishidou Y, et al. Risk factor for bone loss in patients with rheumatoid arthritis treated with biologic diseasemodifying anti-rheumatic drugs. BMC Res Notes 2017;10:1-5.

27. Calsolaro V, Niccolai F, Pasquletti G, Caraccio N. Overt and subclinical hypothyroidism in the elderly: when to treat? Front Endocrinol 2019;10:1-8.

28. Visser WE, Friesema EC, Visser TJ. Minireview: thyroid hormone transporters: knowns and the unknowns. Mol Endocrinol 2011;25:1-14.

29. Williams GR, Bassett JHD. Thyroid disease and bone health. J Endocrinol Invest 2018;41:99-109.

30. Bassett JHD, Williams GR. Role of thyroid hormones in skeletal development and bone maintenance. Endocr Rev 2016;37:135-87.

31. Kim HY, Mohan S. Role of the mechanism of action of thyroid hormone on the skeletal development. Bone Res 2013;1:14661. 
32. Ongphiphadhanakul B, Puavilai G, Rajatanavin R. Effect of TSHsupressive doses of levothyroxine on bone mineral density in thai women. J Med Assoc Thai 1996;79:563-7.

33. Bauer DC, Nevitt MC, Ettinger B, Stone K. Low thyrotropin levels are not associated with Bone loss in older women: a prospective study. J Clin Endocrinol Metab 1997;82:2931-36.

34. Greenspan SL, Greenspan FS, Resnick NM, Block JE, Friedlander JE, Genant HK. Skeletal integrity in premenopausal and postmenopausal women receiving long-term L-thyroxine therapy. Am J Med 1991;91:5-14.

35. Svare A, Nilsen TI, Bjoro T, Forsmo S, Schei B, Langhammer A. Hyperthyroid levels of TSH correlate with low bone mineral density: the HUNT 2 study. Eur J Endocrinol 2009;161:779-86.

36. Roef G, Lapauw B, Goemaere S, Zmierczak H, Fiers T, Kaufman $\mathrm{JM}$, et al. Thyroid hormone status within the physiological range affects bone mass and density in healthy men at the age of peak bone mass. Eur J Endocrinol 2011;164:1027-34.

37. Gogakos AI, Bassett JHD, Williams GR. Thyroid and bone. Arch Biochem Biophys 2010;503:129-36.

38. Krolner B, Jorgensen JV, Nielsen SP. Spinal bone mineral content in myxoedema and thyrotoxicosis. effects of thyroid hormone (s) and antithyroid treatment. Clin Endocrinol 1983;18:439-46.

39. Gharib H, Mazzaferri EL. Thyroxine suppressive therapy in patients with nodular thyroid disease. Ann Intern Med 1998;128:386-94.

40. Pantazi H, Papapetrou PD. Changes in parameters of bone and mineral metabolism during therapy for hyperthyroidism. J Clin Endocrinol Metab 2000;85:1099-6.

41. Nicholls JJ, Brassill NJ, Williams GR, Bassett JHD. The skeletal consequences of thyrotoxicosis. J Endocrinol 2012;213:209-21.

42. Gouveia CHA. The molecular and structural effects of thyroid hormone in the skeleton. Arq Bras Endocrinol Metab 2004;48:183-95.

43. Donangelo I, Walts AE, Bresee C, Braunstein GD. Lymphocytic thyroiditis is associated with an increased number of benign cervical nodes and fewer central neck compartment metastatic lymph nodes in patients with differentiated thyroid cancer. Endocr Pract 2016;22:1192-8.

44. Mudde AH, Reijnders FJL, Kruseman AC. Peripheral bone density in women with untreated multinodular goitre. Clin Endocrinol 1992;37:35-9.

45. Foldes J, Tarjan G, Szathmari M, Varga F, Krasznai I, Horvath C. Bone mineral density is patients with endogenous subclinical hyperthyroidism: Is this thyroid status a risk factor for osteoporosis? Clin Endocrinol 1993;39:521-7.

46. McDermott MT, Perloff JJ, Kidd GS. A longitudinal assessment of bone loss in women with levothyroxine-suppressed benign thyroid disease and thyroid cancer. Calcif Tissue Int 1995;56:521-5.

47. Campos Pastor MM, Lopez-lbarra PJ, Escobar Jimenez F, Serrano P, Garcia Cervigon AG. Intensive insulin therapy and bone mineral density in type 1 diabetes mellitus: a prospective study. Osteoporos Int 2000;11:455-9.

48. Lee JS, Buzkova P, Fink HA, Vu J, Carbone L, Chen Z, et al. Subclinical thyroid dysfunction and incident hip fracture in older adults. Arch Intern Med 2010;170:1876-83.

49. Blum MR, Bauer DC, Collet TH, Fink HA, Cappola AR, Wirth CD, et al. Subclinical thyroid dysfunction and fracture risk: a metaanalysis. J Am Med Ass 2015;313:2055-65.

50. Vadiveloo T, Donnan PT, Cochrane L, Leese GP. The thyroid epidemiology, audit, and research study (TEARS): morbidity in patients with endogenous subclinical hyperthyroidism. J Clin Endocrinol Metab 2011;96:1344-51.

51. Tauchmanova L, Nuzzo V, Del Puente A, Fonderico F, EspositoDel Punete A, Padulla S, et al. Reduced bone mass detected by bone quantitative ultrasonometry and DEXA in pre-and postmenopausal women with endogenous subclinical hyperthyroidism. Maturitas 2004;48:299-306.

52. Garin MC, Arnold AM, Lee JS, Robbins J, Cappola AR. Subclinical thyroid dysfunction and hip fracture and bone mineral density in older adults: the cardiovascular health study. J Clin Endocrinol Metab 2014;99:2657-64.
53. Leader A, Aysenfeld RH, Lishner M, Cohen E, Segev D, Hermoni D. Thyrotropin levels within the lower normal range are associated with an increased risk of hip fractures in euthyroid women, but not men, over the age of $65 \mathrm{y}$. J Clin Endocinol Metab 2014;99:2665-73.

54. Bassett JH, Williams GR. The molecular actions of thyroid hormone in bone. Trends Endocrinol Metab 2003;14:356-64.

55. Williams GR. Actions of thyroid hormones in bone. Endokrynol Pol 2009;60:380-8.

56. Kosińska A, Syrenicz A, Syrenicz M, Kosiński B, Miazgowski T, Garanty-Bogacka B. The influence of treatment with substitutive or suppressive doses of thyroxine on biochemical bone turnover markers. Ann Acad Med Stetin 2005;51:97-104.

57. Vestergaard P, Weeke J, Hoeck HC, Nielsen HK, Rungby J, Rejnmark L, et al. Fractures in patients with primary idiopathic hypothyroidism. Thyroid 2000;10:335-40.

58. Vestergaard P, Rejnmark L, Mosekilde L. Influence of hyper-and hypothyroidism, and the effects of treatment with antithyroid drugs and levothyroxine on fracture risk. Calcif Tissue Int 2005;77:139-44.

59. Ross DS. Bone density is not reduced during the short-term administration of levothyroxine to postmenopausal women with subclinical hypothyroidism: a randomized, prospective study. Am J Med 1993;95:385-8.

60. Davis LB, Lathi RB, Dahan MH. The effect of infertility medication on thyroid function in hypothyroid women who conceive. Thyroid 2007;17:773-7.

61. Aghajanova L, Lindeberg M, Carlsson IB, Stavreus-Evers A, Zhang P, Scott JE, et al. Receptors for thyroid-stimulating hormone and thyroid hormones in human ovarian tissue. Reprod Biomed Online 2009;18:337-47.

62. Kataria J, Gill GK, Kaur M. Interrelationship of thyroid hormones, obesity and prolactin in infertile women. Asian J Pharm Clin Res 2018;11:136-7.

63. Stem L. Thyroid dysfunction and the menstrual cycle. Clinical Advisor Forum 2009. Available from: http://www.clinicaladvisor.com/thyroid-dysfunction-and-themenstrual-cycle/article/138094/ [Last accessed on 04 May 2019]

64. Krassas GE, Poppe K, Glinoer D. Thyroid function and human reproductive health. Endocr Rev 2010;31:702-55.

65. Mansourian AR. Female reproduction physiology adversely manipulated by thyroid disorder: a review of the literature. Pak J Biol Sci 2013;16:112-20.

66. Longcope C, Abend S, Braverman LE, Emerson CH. Androstenedione and estrone dynamics in hypothyroid women. J Clin Endocrinol Metab 1990;70:903-7.

67. Gallagher TF, Fukushima DK, Noguchi S, Fishman J, Bradlow $\mathrm{HL}$, Cassouto J, et al. Recent studies in steroid hormone metabolism in man. Recent Prog Horm Res 1966;22:283-3.

68. Karaca N, Akpak YK. Thyroid disorders and fertility. Int J Res Med Sci 2015;3:1299-304.

69. Saran S, Gupta BS, Philip R, Singh KS, Bemde SA, Agroiya P, et al. Effect of hypothyroidism on female reproductive hormones. Indian J Endocrinol Metab 2016;20:108-13.

70. Vaananen HK, Harkonenb PL. Estrogen and bone metabolism. Maturitas 1996;23:65-9.

71. Goncalves LV, Martins KA, Mota JCMG, Schincaglia RM, Sousa ALL, Junior RF. High bone mineral density of the lumbar spine is positively associated with breast cancer. Biomed Res Int 2019;1-11. https://doi.org/10.1155/2019/8010356

72. Zuo H, Sun A, Gao L, Xue W, Deng Y, Wang Y, et al. Effect of menopausal hormone therapy on bone mineral density in Chinese women: a 2-year, prospective, open-label, randomized controlled trial. Med Sci Monit 2019;25:819-26.

73. Turner RT, Riggs BL, Spelsberg TC. Skeletal effects of estrogen. Endocr Rev 1994;15:275-300.

74. Sunyer T, Lewis J, Collin Osdoby P, Osdoby P. Estrogen's boneprotective effects may involve differential IL-1 receptor regulation in human osteoclast-like cells. J Clin Invest 1999;103:1409-18.

75. Eriksen EF, Langdahl B, Vesterby A, Rungby J, Kassem M. Hormone replacement therapy prevents osteoclastic 
hyperactivity: a histomorphometric study in early postmenopausal women. J Bone Miner Res 1999;14:1217-21.

76. Ginaldi L, Benedetto Di MC, Martinis De M. Osteoporosis, inflammation and aging. Immun Ageing 2005;4:2-14.

77. Pacifici R, Rifas L, Teitelbaum S, Slatopolsky E, McCracken R, Bergfeld $\mathrm{M}$, et al. Spontaneous release of interleukin 1 from human blood monocytes reflects bone formation in idiopathic osteoporosis. Proc Natl Acad Sci USA 1987;84:4616-20.
78. Hopkins SJ, Humphreys M, Jayson MI. Cytokines in synovial fluid. I. The presence of biologically active and immunoreactive IL-1. Clin Exp Immunol 1988;72:422-7.

79. Hughes DE, Dai A, Tiffee JC, Li HH, Mundy GR, Boyce BF. Estrogen promotes apoptosis of murine osteoclasts mediated by TGF- $\beta$. Nat Med 1996;2:1132-6.

80. Lindsay R. Estrogen therapy in the prevention and management of osteoporosis. Am J Obstet Gynecol 1987;156:1347-51. 